\section{A erture}

\author{
on
}

\section{A SERIES OF CASES IN WHICH COLLECTIONS OF STONES FORMED IN THE PROSTATIC URETHRA.}

Delivered at the Medical Graduates' College and PolyClinic.

By CHARLES A. MORTON, F.R.C.S.,

PROFESSOR OF SURGERY IN UNIFERSITY COLLEGE, BRISTOL; SURGEON TO THE BRISTOL GENERAI HOSPITAL AND THE HOSPITAL FOR

$$
\text { CHILDREN AND WOMEN. }
$$

Gentlemen,-As it is uncommon to find collections of stones in the prostatic urethra I thought the records of the following three cases, which have been under my care, might be of interest to you. I wish to make it clear at once that I do not consider that they are cases of prostatic stones, that is, stones formed from the prostatic secretion. within the gland; nor can we, I think, regard them as stones formed within the prostate, but of urinary origin. There is no evidence that they were formed within the prostate. The prostate seems to have disappeared from pressure, or at any rate to be so flattened out as to be unrecognizable, and the stones lay in the greatly dilated, and, in some cases, pouched,prostatic urethra. There can be little doubt that they are cases of urethral calculi, and an interesting question is, Were they formed entirely within the urethra, or did they come originally from the bladder or kidneys, and lie in the urethra, and grow there from accession of phosphatic deposit? And if they came from the kidneys, why did they lie in the prostatic urethra, rather than pass farther down the urethra, or even out of it altogether? And if they never came from the bladder or kidneys, but were formed entirely within the prostatic urethra, why were they so formed? These are the questions which it seems to me we want to answer in our study of these cases; and it will be well, also, to note the symptoms and signs associated with this condition, and to discuss briefly what can best be done to remove the stones, and to prevent their re-formation. To prevent their re-formation seems the great difficulty, at any rate in some cases.

I will now give you an account of the three cases.

$$
\text { Case I. }
$$

A. C., aged 35, was admitted to the Bristol General Hospital, under my care, as a case of stricture, on January 28th, 1901. The urine seemed to be constantly dribbling away, and he never had any stream. There was a history of difficulty with micturition extending over fifteen years, and that instruments had been passed fifteen years ago. There had never been actual retention at any time. Eighteen months before admission there had been painless haematuria every time he passed urine for several weeks, and again after an interval of a fortnight, in which he was free from this symptom, he passed clots for three days with great pain. He had passed a No. 6 soft catheter for himself six months before admission; this was the last time an instrument had been passed. There had been no stream-only dribbling of urine for three months before admission. An attempt had been made to pass a catheter by another surgeon in the out-patient room before admission, but had failed. There had never been much pain with micturition, except on the few days he passed the clots, already referred to; but for twelve years there had been a slight pricking pain at the end of the penis and in the perineum after micturition. This might, however, be absent for several months. There was no history of any sudden stoppage of the stream of urine at the time he had passed it in a stream. He had suffered from pain in both loins as long as he had had difficulty in micturition.

The bladder was not distended. The urine contained a tenacious mass of pus floating in it. I passed no instrument for several days after admission, as at first he had some pyrexia. I then passed Lister's sounds up to 2.5 without much trouble, but I did not then detect the stones, and regarded the case as one of stricture only; but a few days later I again passed the same sized sound (2.5), and at once struck a stone in the deep urethra, nor could I get it past the stone this time
Examination per rectum revealed a large irregular stone lying in the position of the prostate, and it felt as if only the mucous membrane of the rectum lay between the finger and the stone. When under the anaesthetic another rectal examination revealed the fact that several stones were present, and that they grated on one another. This time the 2.5 Lister's sound passed into the bladder

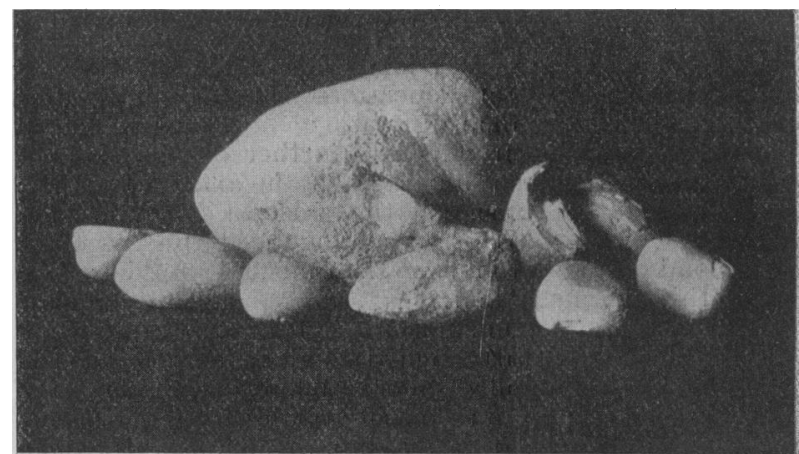

Fig. 1.-Stones removed at first operation in Case 1. The branched stone lying in front of the large stone is the one facet can be seen. The stone on the right of the large stone has been bisected. The photograph represents the actual șize of the stones.

easily, and also a No. 5 grooved staff, on which I opened the urethra just in front of the anus. It was greatly dilated, and pouched in a downward direction, and full of stones, The largest I had to extract with small lithotomy forceps, the others I turned out readily with my fingers. The neck of the bladder was easily made out, and the finger passing through it detected one stone witkin the bladder,

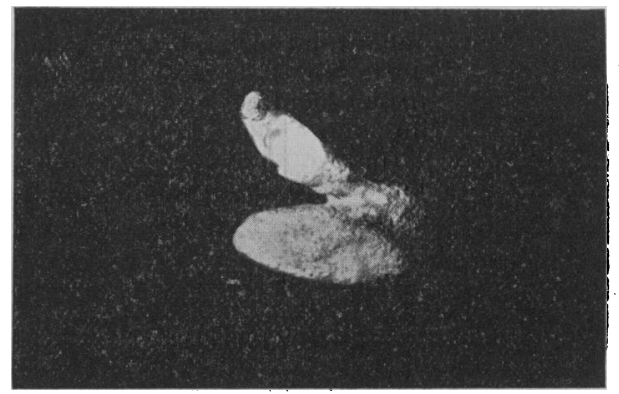

Fig. 2.-The stone removed from the bladder in Case 1 at first operation. It is seen in the photograph of the group of stones removed at the first operation the actual size of the stone: in this photograph it is very slightly magnified in the photographic

which was removed. A sound passed into the bladder failed to detect any more. The walls of the pouch were smooth, and all trace of the prostate had disappeared. I found there was a stricture in the scrotal portion of the urethra, and this I dilated with Lister's sounds, and tied in a full-sized catheter. There were seven stones, and three minute concretions in the pouch in the prostatic

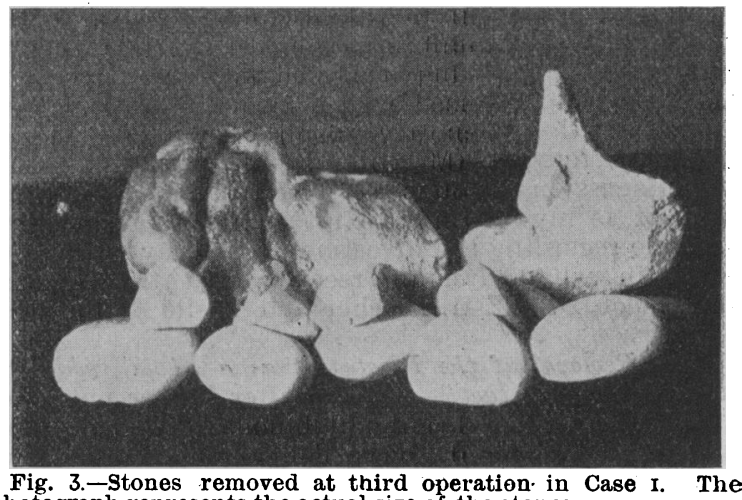

Fig. 3.- Stones removed at third operation in
photograph represents the actual size of the stones.

region, one in the bulbous urethra, as well as one in the bladder. Many were faceted. The largest stone (which was one of those in the pouch) was $1 \frac{1}{8} \times 1$ in., and weighed 208 grains. It is composed entirely of phosphates. There appeared to be a minute nucleus of uric acid, and a layer near the periphery looks like uric acid, but a chemical 
examination does not show any trace of uric acid. All the other stones I have sectioned seem to be entirely phosphatic. The stone found in the bladder is of a very remarkable shape, like two stones joined at an acute angle, and on one branch is a small facet. This stone was probably partly urethral, and projected into the bladder, into which it eventually slipped. I. have not made a section of it to determine the structure of its interior, in order not to destroy its remarkable shape, so I cannot say whether it is entirely composed of phosphates or not.

The catheter was retained for a few days only, and then the urine came for a time by the perineal wound. This healed in April, and he.was then much better, had gained flesh, and passed urine without pain every two hours, and he was able to get out in the exercise ground of the hospital but early in May he began to suffer from pain above the pubes, associated with sudden stoppage of his urine, and a stone was discovered in the prostatic urethra. He also had more pain in the loins since he had been getting about freely, and a skiagram was taken to see if there were any indication of stone in the kidney, but it did not show any.

On May 10th I again explored the urethra and found the old pouch empty, but I detected the point of a stone projecting into it from a cavity on the right, and in dilating the orifice I found it contained several stones, two branched like renal stones and a few smaller ones. The cavity seemed to extend backwards under the bladder, and was not quite as smooth as the pouch originally emptied. I could feel no stones within the bladder this time. I have no note as to when the perineal wound healed, but a few months after the operation he passed two small stones, and several were felt by me in the urethra but they did not cause any trouble for some time after that.

He came under my care again rather more than two years later (October, 1903), and then the urine only dribbled away, and he had much pain with micturition, very disturbed nights, and his urine was very ammoniacal, and contained much pus. Stones could be easily felt in the deep urethra. He still had the loin pain on both sides, and he said it extended into the groin, and was worse on the right side. A skiagram of the kidneys was again taken, but with negative result. I removed fifteen stones from the prostatic pouch, and he returned home in the following month, when the perineal wound completely closed. No stones were found in the bladder. After the removal of the stones, until they formed again, he was free from the loin pain, but unfortunately they very quickly re-formed. I had to remove two more in the following February (1904), and in June the house-surgeon removed one which was impacted in the urethra and which caused retention; and again in November, 1904, I had to remove some stones from the pouch, and a stone which was fixed in the urethra had to be removed by an incision in the peno-scrotal junction. At this time I decided to explore the kidney on the side in which he had most pain, but found no stones in it. The last operation was in March, 1905, when numerous small stones were extracted from the pouch and some from the urethra between two strictures at the peno-scrotal junction. I saw him again last February. He said he passed small stones occasionally, and felt sure there were some in his urethra. I did not feel any from the perineum, but I did not examine from the rectum. I also dilated the strictures fully with Lister's sounds, but did not detect any stones. He had no pain with micturition, but a fistula persisted in the perineum from the last operation. He was able to work as a painter again, and looked better than I had seen him for several years. He has thus had stones removed by incision six times; once a stone which caused retention was removed by forceps, and he has frequently passed stones.

\section{Case II.}

The patient, H. W., aged 34 , was admitted into the Bristol General Hospital, December 6th, 1904. There was a history of retention of urine when a boy, which was relieved by some operation on the end of the penis, and, from the appearance of the orifice of the urethra, the meatus had apparently been slit up, perhaps to extract an impacted stone. He told me that from this time he had suffered from incontinence. Nine months before admission he had had a catheter passed for retention, and a month later two stones were removed from the scrotal portion of the urethra by incision, and there a urinary fistula remained, through which the greater portion of the urine came. There was a slight stricture not far from the meatus, which was easily dilated to a certain extent, but the smallest size sound was obstructed in the perineum, and in the prostatic region two stones could be felt grating on one another per rectum. The urine was ammoniacal and contained pus. On December 20th I opened the urethra in the same place as in the last case, and removed from the prostatic urethra a stone the size of a small marble, which had broken into two pieces. The prostatic urethra was not only dilated, but was considerably elongated, so that it was difficult to reach the neck of the bladder, but I did so, and also sounded the bladder, but with negative result. The stricture was fully dilated when he was under the anaesthetic. The perineal wound was healed when he left the hospital at the end of a month after the operation, but the fistula was not. The prostatic urethra was so dilated that by pressure on it a stream of urine could be forced out of the fistula.

\section{Case III.}

T. F., aged 63 , was sent to me by his doctor with stricture, perineal fistula, and recurring scrotal abscesses. He had had Wheelhouse's operation performed by another surgeon many years before, and the fistula remained from that. He had been able to pass an instrument for himself until one year ago, but since then had failed to get it in. The urine was ammoniacal and contained pus. I found a stricture at the junction of the penis and scrotum, but under an anaesthetic easily dilated it to the full; but the large-sized sound was very tightly gripped all along the deep urethra. In passing the sounds I found stones in the prostatic region, and they could be easily felt per rectum. On January 31st I cut through the scar tissue of the old Wheelhouse into the urethra and removed from a greatly dilated prostatic portion several fragments of stone, which altogether weighed 95 gr. ; this stone is partly composed of calcium oxalate. I could just reach the neck of the bladder beyond, and I sounded the bladder with negative result. The prostate seemed to have disappeared, the floor of his pouch being apparently formed of the urethral and rectal walls only. The fistulous track was dissected out, and its walls brought together with catgut, and a large-sized catheter tied in. He was much relieved by the operation, but the fistula was not cured.

In all these cases the presence of the stone was associated with a stricture of the urethra, and thus the passage of stones out of the urethra was obstructed. It was not a very tight stricture in any of the cases, and was easily dilated to a considerable extent; but still it was enough to obstruct any calculus. But how were the stones formed? The prostatic urethra may dilate behind a stricture to a very considerable extent, and the urine remaining in the dilated urethra after micturition may no doubt deposit phosphates and so form calculi. That such a collection of urine did take place was shown by the fact that in Case II urine could be emptied out of the dilated part of the urethra by pressure. In none of the cases, however, was the stricture just in front of the prostatic urethra. In one case it was scrotal, in another at the junction of penis and scrotum, and in the third quite near the meatus; and hence we might expect a more general dilatation of the urethra behind the stricture. Moreover, the stricture was not as tight as one would expect a stricture to be if it were the cause of such marked dilatation behind the obstruction, and in none of the cases had the stricture been dilated for many months.

In Case I the rapidity of the formation of the stones after removal was very striking, and also the way in which a collection was discovered at the second operation in a cavity only communicating with the urethra by an opening through which a part of one of the stones projected, when no such cavity containing stones had been recognized at the first operation. They might have been present as very small stones shut off in this cavity at the time of the first operation. But they were of such size at the time of the second operation, three months later, that. they were discovered by palpation from without. It is, of course, well known that stones may pass out of the urethra into the surrounding tissue and grow there, and the original track become a mere fistula. In this case it seems more likely that a part of the original pouch got shat 
off by contraction, and the stones formed in it after the first operation.

So far as I know only phosphatic stones are formed in the urethra (though true prostatic calculi containing a certain amount of organic material may get loose into it), and thus if any of these stones contain oxalates or uric acid, they must have passed into the urethra from higher up in the urinary organs, but failed to get away, on account of the strictured condition of the tube, as they undoubtedly did in a case to which I shall refer at the end of this lecture. They would then grow there by accession of phosphates, and by their growth might dilate the prostatic urethra into the pouched condition in which I found it, or if composed of phosphates only they might come originally from the bladder or kidneys. But if they came from the bladder or kidneys, with the strictures 80 far forward, why should they lodge especially in the prostatic urethra? In Cases I and II one would expect them to lodge just behind the stricture, or to form a ball valve obstruction, as stones in the common bile duct so often do, and dilate the whole canal behind the stricture. Perhaps they did so at first, and then falling back into the prostatic urethra at the end of the act of micturition at any rate when the patient was in the recumbent position, as they increased in size, at last they became too large to pass out of the region of the urethra. But there was no history of repeated attacks of temporary retention or intermittent stream which one would expect with ball valve obstruction. It was the idea that the stones might possibly be formed in the kidneys, and simply lie in the urethra, detained there by the stricture, that induced me to have several skiagrams of the kidneys taken in Case $x$, and to finally explore the kidney on the side on which he had the most lumbar pain, but all with negative result. I presume the lumbar pain was reflected pain from the prostatic region, and the fact that it was relieved by removal of the stones pointed to this cause, but we must remember that associated with such removal there was always a period of rest which might relieve pain from renal calculus.

In Case III, as the stone was largely composed of oxalates, it must have come originally from the bladder and kidney. In this case the urethra in front of the prostatic pouch was so contracted by the scar tissue of the old Wheelhouse's operation that it is not surprising the stone lodged in the prostatic urethra.

All the stones from Case I which I have sectioned are entirely phosphatic, and might, therefore, have been formed where they were found. You will remember that one stone was actually found in the bladder, but as it is of such remarkable shape, and has a little facet on it, I feel sure it must have been originally urethral, probably with one branch extending into the bladder. Mr. Henry Morris, in his book on Injuries and Diseases of the GenitoUrinary Organs, figures a stone somewhat resembling it, but larger, whioh lay partly in the urethra and partly in the neck of the bladder.

The stone in Case II, you will remember, was also entirely phosphatic. As dilatation and pouching of the urethra behind a stricture often occurs to a marked degree, and though, as I have already suggested in these cases, the strictures were hardly tight enough, one would think, to cause so much dilatation, and the great dilatation seemed so far back behind the stricture, yet I think the view that in Cases I and II the pouches were primary and due to the obstruction, and the stones were formed in them, is probably the correct one. We know that in Case I, although the urethral pouch was frequently refilled by stones of some size, yet skiagrams of the kidneys failed to show any there, nor did actual exploration of the right kidney reveal any.

I have already stated that I do not regard the stones as of prostatic origin in any of the cases, neither formed from concretions in the prostate gland, nor of urinary origin within the prostate. In none of these cases, either with the finger in the pouch or the finger in the rectum could any trace of the prostate be made out; it seemed to have been completely flattened out by the dilatation of the prostatic urethra. The stones were therefore obviously not in the gland, nor were they of such character as one would expect to have' been of prostatic origin.

It is interesting to note how little pain may be present with quite a large collection of stones in the prostatic urethra, as in Case $\mathrm{I}$ at the time of admission. Neither in Case II or III was there pain with micturition. The painless haematuria lasting for several weeks was also a symptom worth noting. It is said to occur in cases in which stones are formed and remain in the prostate gland.

These cases show that even the passage of a stricturedilating sound will not always lead to the detection of the stones in the prostatic urethra. In Case I a 2.5 Lister's sound could, the first time I introduced it, be passed into the bladder without detecting the stones, but the second time I passed it I discovered them in its passage. The stone in Case IIr was also discovered by passing a stricture sound, but in Case II the cause of the obstruction in the perineum was not made out by the instrument, but only by a rectal examination made to guide the point of the catheter through a supposed stricture. Only once in any of the cases did a stone get so impacted in the narrower part of the urethra as to cause retention, although there was a stricture in all.

With regard to treatment there is not much to be said. A perineal section to remove the stones, together with dilatation of any stricture or strictures, is clearly indicated, and to prevent the re-collection of the stones, it is desirable to keep the stricture well dilated, so that the stones may have the chance to pass when small. At one time in Case I I endeavoured to establish a perineal fistula so that urine might not remain and deposit in the dilated part of the urethra, but I could not keep the drainage tube in long enough, and the wound completely healed. Since the last operation, however, a perineal fistula has remained, but it has not stopped the formation of stones, for he frequently passes small ones. Correction of the alkaline condition of the urine by washing out the bladder, and the administration of drugs might also diminish the tendency to phosphatic deposit in the urethra, but it is possible that in some of these cases ammonical urine may not come from the bladder, but only from the urethral pouch. If so a catheter passed very slowly would draw this off first, and then afterwards urine of a different character from the bladder.

Mr. Henry Morris, in his book on Injuries and Diseases of the Genito-Urinary Organs to which I have already referred, records a case in which he removed four stones from the dilated prostatic urethra. As he could get a lithotrite passed into the bladder, there could have been no stricture in this case, unless he had previously dilated one, but he does not state that he did so. The patient, who was an elderly man, had previously had both lithotrity and lithotomy performed. Eighteen months after the removal of these stones, Mr. Morris removed another from the same place. He refers to a very remarkable case which was under the care of another surgeon. In a boy, a large stone lay in a urethral pouch in the perineum and occasionally caused retention, which was relieved by the boy lying on his back; so that the stone acted as a ball valve at times. Dr. Thistle ${ }^{1}$ records a ne in which retention was associated with a fluctuating swelling in the perineum. This was formed partly by the urethra, greatly dilated, behind a very tight stricture partly by an abscess cavity. The urethral pouch extended par a bind the neck of the bladder, and container three uric acid stones. As these stones were of uric acid they must have passed into the urethra from the bladder, and been retained there by the stricture.

\section{REFERENCE.}

1 Lancet, 1892 ii, p. 1330

International Congress of Hygiene. - The fourteenth meeting of the International Congress of Hygiene and Demography will be held in Berlin from September 23rd to Septemer 29th, 1907. The work of the Congress will be distributed among eight sections, as follows: (1) Hygienic Microbiology and Parasitology; (2) Hygiene of Nutrition and Hygienic Physiology ; (3) Hygiene of Childhood and School Life ; (4) Industrial Hygiene ; (5) The Prevention of Infectious Diseases and the Cure of Patients Suffering Therefrom ; (6) $a$, Hygiene of the Dwelling and the Community ; $b$, Hygiene of Traffic ; (7) Military, Colonial, and Marine Hygiene ; (8) Demography. An exhibition to be held in connexion with the Congress is being organized under the direction of Professor Rubner of Berlin. The General Secretary of the Congress is Dr. Nietner, 9, EichGeneral secretary of the Congress is Dr. should be addressed. 